\title{
Sporadic Creutzfeldt-Jakob disease: a rare cause of rapid cognitive decline in a patient with systemic lupus erythematosus
}

\author{
${ }^{1}$ I Costello, ${ }^{2} \mathrm{R}$ Phadke, ${ }^{3} \mathrm{~N}$ Shah \\ ${ }^{1}$ Core Medical Trainee in Medicine for the Elderly, Leicester Royal Infirmary; ${ }^{2}$ Locum Consultant Neuropathologist, UCL Institute of \\ Neurology, London; ${ }^{3}$ Consultant in Medicine for the Elderly, Leicester Royal Infirmary, Leicester, UK
}

ABSTRACT An immunocompromised patient with non-specific neurological symptoms and signs, along with rapid cognitive decline evolving over three to four weeks, can present a diagnostic challenge. Here we report rapidly progressive dementia in a patient with systemic lupus erythematosus, who was subsequently diagnosed with sporadic Creutzfeldt-Jakob disease (sCJD). This case illustrates the need for prompt investigations to consider an alternative diagnosis where significant history fails to yield an explanation. A diagnosis of $\mathrm{SCJD}$ drastically alters the prognosis in a subject with a well-controlled connective tissue disease who is otherwise fit and well.
Correspondence to $\mathbf{N}$ Shah, Leicester Royal Infirmary, Infirmary Square, Leicester LEI 5WW, UK

tel. +44 (0) II 62585057 e-mail shahnainal@hotmail.com

KEYWORDS Dementia, sporadic Creutzfeldt-Jakob disease, systemic lupus erythematosus

DECLARATION OF INTERESTS No conflict of interests declared.

A 68-year-old woman who was previously fully independent and managed the catering at a sports club, presented with an altered personality, low mood, reduced appetite and weight loss evolving over four months. An endoscopy two months previously showed oesophagitis, gastritis and positivity for Helicobacter pylori, which was eradicated. In June, one month prior to presentation, she had visited relatives in New England, USA, for three weeks. On returning, her husband noted she was confused and had poor concentration, difficulty communicating, decreased mobility and urinary incontinence. There was no history of tick bites or a rash and no symptoms suggestive of seizure. The patient's medical history was of systemic lupus erythematosus (SLE) since 1991, which was well controlled with prednisolone and azathioprine, and osteoporosis. There was no previous history suggestive of cerebral lupus, hypertension, stroke or ischaemic heart disease. She had not received blood transfusion nor had any neurosurgery. There was no family history of dementia.

On examination the patient appeared alert but vocalised only a few words. She had slow responses to commands, apraxia, mask-like facies, nominal dysphasia, right-sided cogwheel rigidity and a shuffling gait. Her abbreviated mental test score was $0 / 10$. Blood pressure was normal and there was no fever. There was no myoclonus and no rash.

The working differential diagnosis at this stage included cerebrovascular disease with vascular Parkinsonism, fungal or viral encephalitis, Lyme disease, cerebral SLE and other forms of chronic dementia.

Initial investigations revealed a normocytic anaemia and mild lymphopenia, normal inflammatory markers, normal serum $\mathrm{BI}$, folate and thyroid function tests. The

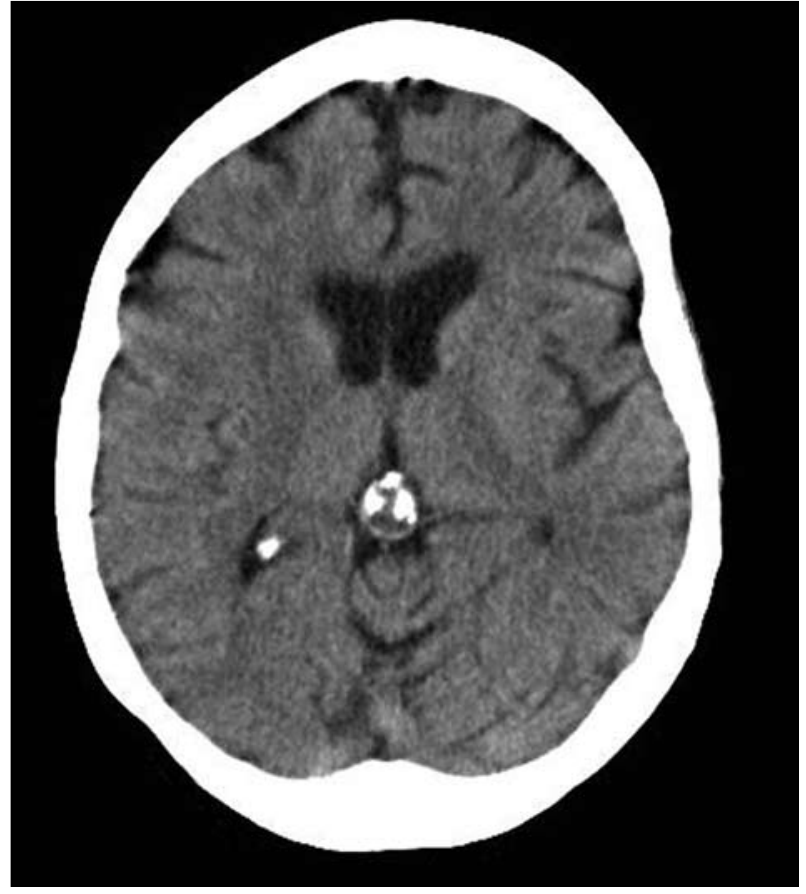

FIGURE I Computed tomography head scan showing a mild burden of small-vessel cerebrovascular disease.

patient's electrocardiogram and chest $X$-ray were normal. A computed tomography (CT) head scan showed a mild burden of small-vessel cerebrovascular disease (Figure I).

Further investigations revealed negative viral screen (Epstein-Barr, cytomegalovirus, herpes simplex and varicella zoster) and antibody serology, including to Borrelia burgdorferi, human immunodeficiency virus and Treponema pallidum. The anti-nuclear antibody level was raised $(1: 6,400)$, with negative anti-double-stranded- 


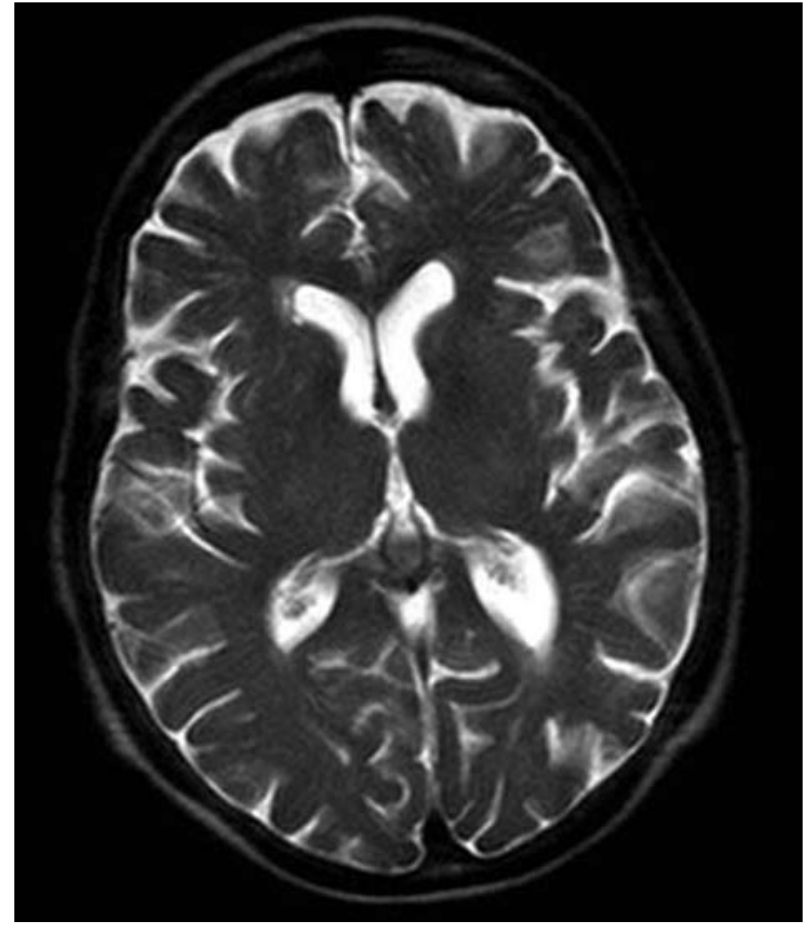

FIGURE 2 Magnetic resonance imaging of the brain, showing no signal abnormality.

DNA (anti-dsDNA), anti-cardiolipin and anti-neutrophil cytoplasmic antibodies. Complement components 3 and 4 were normal. On lumbar puncture, opening pressure was normal. Cerebrospinal fluid (CSF) microscopy, cell count and biochemistry were normal. Special stains for micro-organisms (Gram and India ink) and CSF culture were negative. Treponemal antibody was not detected. On further investigations, magnetic resonance imaging (MRI) of the head (diffusion weighted, fluid attenuating inversion recovery sequence [FLAIR], arterial and venous phase imaging) showed no significant abnormalities, although the scan was sub-optimal due to patient movement (Figure 2).

As all investigations so far remained inconclusive of the above differential diagnosis, the history was revisited and an alternative diagnosis was sought. The history confirmed the absence of previous neurological or cognitive impairment and the definite rapid cognitive decline over three to four weeks. The patient's husband provided e-mail correspondence from the relative in New England, which was suggestive of rapid declining cognition without hallucination over her three-week visit (as the relative described it, 'she can't get her brain to work properly'). The patient needed constant prompts for each task or activity of daily living. She treated many everyday activities as if she had never done them before.

This prompted us to arrange an electroencephalograph (EEG) and preserve a CSF sample for testing for Creutzfeldt-Jakob disease (CJD). The EEG showed periodic sharp wave complexes (PSWC), I-2 per

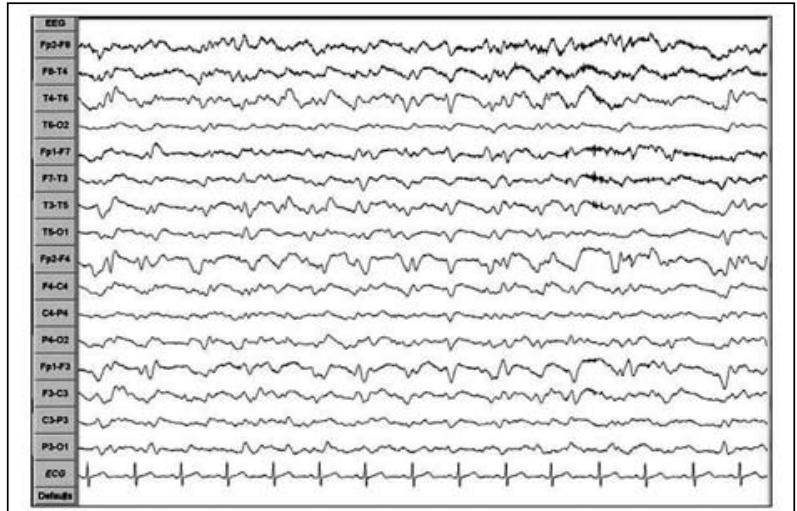

FIGURE 3 Electroencephalograph showing periodic sharp wave complexes, I-2 per second (settings: sensitivity 100 $\mu \mathrm{V} / \mathrm{cm}$, time constant $0.30 \mathrm{~s}$, filter $70 \mathrm{~Hz}$ ).

second, suggesting a diagnosis of sporadic CJD (sCJD) (Figure 3). Cerebrospinal fluid sent to the National CJD Surveillance Unit subsequently showed 14-3-3 protein and raised serum SIOOB, supporting this diagnosis.

The patient received end-of-life care. The prion gene was sequenced and no mutation detected. She deteriorated rapidly and died six weeks after presentation. A postmortem neuropathological examination of the brain confirmed sCJD (Figure 4, overleaf). The prion protein gene analysis showed no mutations. The codon 129 genotype was methionine homozygous.

\section{DISCUSSION}

This report describes a rare condition, $s C J D$, co-existing with SLE. Our report is the first documented case of SLE and SCJD in the same patient.

The true diagnosis was only considered after a careful review of the case history and selective investigations to exclude alternatives. Routine blood tests refuted systemic inflammation, and a normal CT head scan ruled out a focal intracranial lesion. More common causes of dementia such as Alzheimer's, Lewy body and vascular dementias were considered, but none fully explained the spectrum of symptoms and the short, progressive duration. Given the patient's use of immunosuppressants, viral or fungal encephalitis was considered, but CSF analysis refuted this. The tick vectors for Lyme disease are prevalent in New England and neuroborreliosis can induce encephalitis and altered mental status. ${ }^{1,2}$ The poor temporal correlation of symptom onset with exposure, negative Borrelia burgdorferi serology and the absence of pleocytosis on CSF analysis did not, however, support this diagnosis.

Central nervous system (CNS) involvement is a common feature of SLE. ${ }^{3}$ Although various neurological manifestations occur in $50-70 \%$ of cases of SLE, the brain MRI remains normal. ${ }^{4}$ The patient's history of SLE raised this possibility, although clinically the disease 


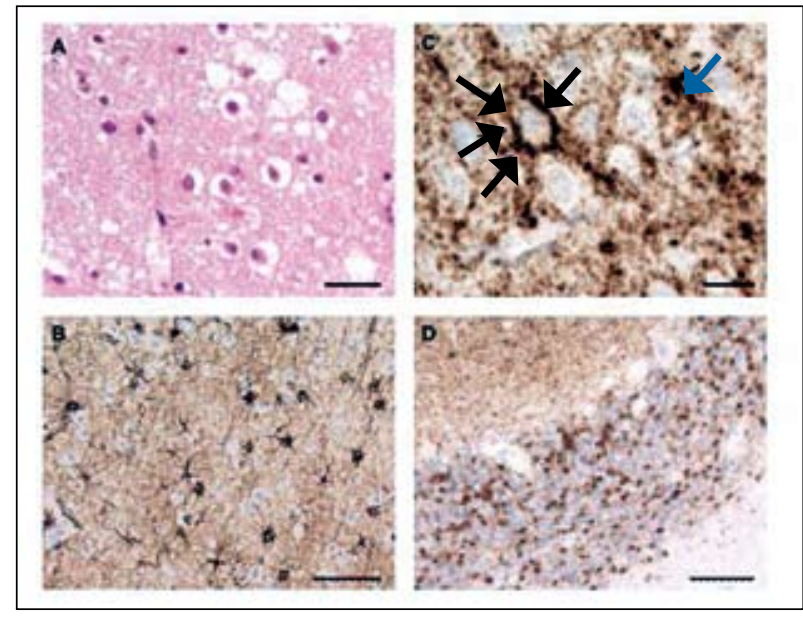

FIGURE 4 The neocortex showed widespread spongiform change with coarse vacuolation of the neuropil (A), accompanying reactive cellular gliosis (B) and widespread transcortical deposition of PrPSc (the misfolded, diseaseassociated form of prion protein) in a diffuse synaptic, perivacuolar and perineuronal pattern ( $\mathrm{C}$, arrows) as well as dense plaque-like deposits (C, blue arrow). The cerebellum showed diffuse synaptic deposits of PrPSc in the molecular layer and larger, coarser deposits in the granular cell layer (D). This pattern was in keeping with $s C J D$. (Scale bar: $A=50$ $\mu \mathrm{m}, B=20 \mu \mathrm{m}, C, D=100 \mu \mathrm{m}$. Stain used in A: haematoxylin and eosin. Stain used in B, C, D: immunoperoxidase with antibody to prion protein ICSM35. Brown staining represents prion protein deposits.)

appeared quiescent. A low cognitive score for an individual is a poor predictor of the presence of CNS involvement. ${ }^{5}$ Persistent positive anticardiolipin and antiphospholipid antibody are found to be associated with cognitive impairment in SLE, but it is unclear if this is associated with cerebral SLE. ${ }^{6,7}$ In our case, anticardiolipin and antiphospholipid antibody were negative. Also, raised anti-dsDNA antibody titres tend to reflect disease activity, but these were undetectable.

Sporadic CJD has an annual incidence of one per million UK population and a mean age of onset of 65 years. Initial symptoms are often non-specific and can include personality changes, insomnia, anorexia and depression. Typically, rapid cognitive decline, myoclonus, ataxia and pyramidal or extrapyramidal signs develop. ${ }^{8,9}$ The clinical picture of a rapid cognitive decline in this patient fitted well with this diagnosis and prompted us to send a CSF sample to the National CJD Surveillance Unit and to arrange an MRI and an EEG after initial investigations were unfruitful. The typical EEG pattern described above has a reported specificity of $87 \%$ in sCJD. ${ }^{10}$ Cerebrospinal fluid I4-3-3 protein presence and raised SIOOB are found to be sensitive even in early stages of SCJD (reported as 96\%)," but non-specific unless in the right clinical context. Magnetic resonance imaging changes in $S C J D$ are recognised, ${ }^{12-14}$ but there was no signal abnormality within the brain on T2-weighted, FLAIR and diffusion imaging in this patient. A lack of signal abnormality on the MRI does not exclude a diagnosis of sCJD.
TABLE I Diagnostic criteria for probable sporadic Creutzfeldt-Jakob disease

\begin{tabular}{|l|l|}
\hline WHO'5 & UCSF'6 \\
\hline $\begin{array}{l}\text { Progressive dementia } \\
\text { and at least two out of } \\
\text { the following four clinical } \\
\text { features: }\end{array}$ & $\begin{array}{l}\text { Progressive dementia } \\
\text { with } \geq 2 \text { of the following: }\end{array}$ \\
\hline Myoclonus & Myoclonus \\
\hline $\begin{array}{l}\text { Visual or cerebellar } \\
\text { disturbance }\end{array}$ & Visual disturbance \\
\cline { 2 - 2 } $\begin{array}{l}\text { Pyramidal/extrapyramidal } \\
\text { dysfunction }\end{array}$ & $\begin{array}{l}\text { Pyramidal/extrapyramidal } \\
\text { dysfunction }\end{array}$ \\
\hline Akinetic mutism & Akinetic mutism \\
\cline { 2 - 2 } $\begin{array}{l}\text { Higher focal cortical sign } \\
\text { (aphasia, neglect, apraxia) }\end{array}$ \\
\hline $\begin{array}{l}\text { AND a typical } \\
\text { electroencephalograph } \\
\text { during an illness of any } \\
\text { duration }\end{array}$ & $\begin{array}{l}\text { AND a typical } \\
\text { electroencephalograph or } \\
\text { magnetic resonance imaging } \\
\text { scan during an illness of any } \\
\text { duration }\end{array}$ \\
\hline $\begin{array}{l}\text { AND/OR a positive I4-3-3 } \\
\text { cerebrospinal fluid assay and } \\
\text { a clinical duration to death } \\
<2 \text { years }\end{array}$ & \\
\hline $\begin{array}{l}\text { Routine investigations should } \\
\text { not suggest an alternative } \\
\text { diagnosis }\end{array}$ & $\begin{array}{l}\text { Routine investigations should } \\
\text { not suggest an alternative } \\
\text { diagnosis }\end{array}$ \\
\hline
\end{tabular}

The World Health Organization's (WHO) diagnostic criteria for 'probable CJD' include 14-3-3 protein and EEG findings. ${ }^{15}$ Magnetic resonance imaging brain changes in SCJD are included in the University College of San Francisco (UCSF) criteria, ${ }^{16}$ but not the WHO diagnostic criteria (Table I). Definitive diagnosis requires neuropathological examination.

\section{CONCLUSION}

This case serves as a reminder that where a patient has a known chronic diagnosis which appears to explain a new presentation, it can actually be caused by a co-existing rare condition. Alternative diagnoses should be considered when significant history fails to yield an explanation. Post-mortem histopathological examination can provide the definitive diagnosis when a rare disease is suspected during life and should be actively sought in such cases. Sporadic CJD remains a rare and untreatable cause of rapid cognitive decline in older people.

Acknowledgement Dr Ram Vaidyanathan, Consultant Radiologist, University Hospitals of Leicester NHS Trust, Leicester, for help with the neuro-radiology slides. Professor Sebastian Brandner, Professor and Chair of Neuropathology, UCL Institute of Neurology, London for help and guidance with the histopathology slides. 


\section{REFERENCES}

I Halperin JJ. Nervous system Lyme disease: diagnosis and treatment. Rev Neurol Dis 2009; 6:4-12.

2 Mygland A, Ljøstad U, Fingerle $V$ et al. EFNS guidelines on the diagnosis and management of Lyme neuroborreliosis in Europe. Eur J Neurol 20 I0; I7:8-16. doi: I0.1 I I I/j. I468-I33I.2009.02862.x

3 Jennekens FG, Kater L. The central nervous system in systemic lupus erythematosus. Part I. Clinical syndromes: a literature investigation. Rheumatology 2002; 41:605-18. doi:10.1093/ rheumatology/4I.6.605

4 Graham JW, Jan W. MRI and the brain in systemic lupus erythematosus. Lupus 2003; 12:89I-6. doi:10.1 I9I/096 I203303/u4980a

5 Hay EM. Psychiatric disorder and cognitive impairment in SLE. Lupus 1994; 3:145-8. doi:10.I I77/096/20339400300303

6 Hanly JG, Hong C, Smith S et al. A prospective analysis of cognitive function and anticardiolipin antibodies in systemic lupus erythematosus. Arthritis Rheum 1999; 42:728-34. doi:10.1002/I5290I3I(I99904)42:4<728::AID-ANR I6>3.0.CO;2-O

7 Denburg SD, Denburg JA. Cognitive dysfunction and antiphospholipid antibodies in systemic lupus erythematosus. Lupus 2003; I2:883-90. doi:I0.1 I9|/096 I203303/u497oa

8 Zerr I, Poser S. Clinical diagnosis and differential diagnosis of CJD and vCJD. With special emphasis on laboratory tests. APMIS 2002; I 10:88-98. doi:I0.1034/j. I600-0463.2002.I00 I I I.x

9 Shah N, Agbobu A, Costello I et al. Sporadic Creutzfeldt-Jacob disease in older people. Rev Clin Gerontol 2009; 19:207-I5. doi:10.1017/S0959259809990335
10 Iwasaki Y, Mimuro M, Yoshida M et al. Clinical diagnosis of Creutzfeldt-Jakob disease: accuracy based on analysis of autopsyconfirmed cases. J Neurol Sci 2009; 277:119-23. doi:10.1016/j. ins.2008.10.026

II Pennington C, Chohan G, Mackenzie J et al. The role of cerebrospinal fluid proteins as early diagnostic markers for sporadic Creutzfeldt-Jakob disease. Neurosci Lett 2009; 455:56-9. doi:I0.1016/j.neulet.2009.02.067

12 Shiga Y, Miyazawa K, Sato S et al. Diffusion-weighted MRI abnormalities as an early diagnostic marker for Creutzfeldt-Jakob disease. Neurology 2004; 63:443-9.

I3 Young GS, Geschwind MD, Fischbein NJ et al. Diffusion-weighted and fluid-attenuated inversion recovery imaging in CreutzfeldtJakob disease: high sensitivity and specificity for diagnosis. Am J Neuroradiol 2005; 26:155I-62.

14 Zerr I, Kallenberg K, Summers DM et al. Updated clinical diagnostic criteria for sporadic Creutzfeldt Jakob disease. Brain 2009; | 32:2659-68. doi: |0.1093/brain/awp |9|

15 World Health Organization. Human transmissible spongiform encephalopathies. Wkly Epidemiol Rec 1998; 47:36I-5.

16 Geschwind MD, Josephs KA, Parisi JE et al.A 54-year-old man with slowness of movement and confusion. Neurology 2007; 69: I88I-7. doi:I0.I2I2/0I.wnl.0000290370.14036.69

\section{INVITATION TO SUBMIT PAPERS}

We would like to extend an invitation to all readers of The Journal of the Royal College of Physicians of Edinburgh to contribute original material, especially to the clinical section. The JRCPE is a peer-reviewed journal with a circulation of 8,000 . Its aim is to publish a range of clinical, educational and historical material of crossspecialty interest to the College's international membership.

The JRCPE is currently indexed in Medline, Embase, Google Scholar and the Directory of Open Access Journals. The editorial team is keen to continue to improve both the quality of content and its relevance to clinical practice for Fellows and Members. All papers are subject to peer review and our turnaround time for a decision averages only eight weeks.

We would be pleased to consider submissions based on original clinical research,

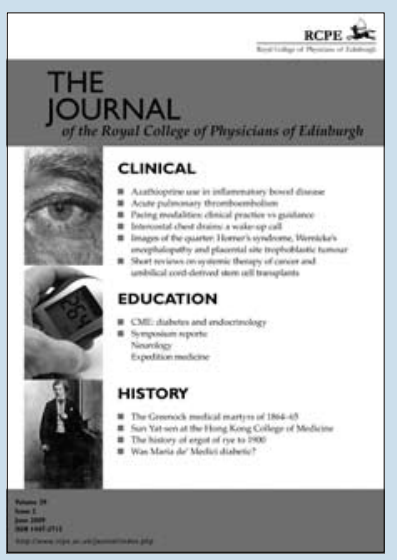
including pilot studies. The JRCPE is a particularly good forum for research performed by junior doctors under consultant supervision. We would also consider clinical audits where the 'loop has been closed' and a demonstrable clinical benefit has resulted.

For further information about submissions, please visit: http://www.rcpe.ac.uk/journal/contributers.php or e-mail editorial@rcpe.ac.uk.Thank you for your interest in the College's journal.

The editorial team,

The Journal of the Royal College of Physicians of Edinburgh 